\title{
Assessing the Option to Abandon an Investment Project by the Binomial Options Pricing Model
}

\author{
Salvador Cruz Rambaud and Ana María Sánchez Pérez \\ Departamento de Economía y Empresa, Universidad de Almería, La Cañada de San Urbano, s/n, 04120 Almería, Spain \\ Correspondence should be addressed to Salvador Cruz Rambaud; scruz@ual.es
}

Received 20 September 2015; Revised 16 December 2015; Accepted 17 January 2016

Academic Editor: Kwai S. Chin

Copyright ( 92016 S. Cruz Rambaud and A. M. Sánchez Pérez. This is an open access article distributed under the Creative Commons Attribution License, which permits unrestricted use, distribution, and reproduction in any medium, provided the original work is properly cited.

\begin{abstract}
Usually, traditional methods for investment project appraisal such as the net present value (hereinafter NPV) do not incorporate in their values the operational flexibility offered by including a real option included in the project. In this paper, real options, and more specifically the option to abandon, are analysed as a complement to cash flow sequence which quantifies the project. In this way, by considering the existing analogy with financial options, a mathematical expression is derived by using the binomial options pricing model. This methodology provides the value of the option to abandon the project within one, two, and in general $n$ periods. Therefore, this paper aims to be a useful tool in determining the value of the option to abandon according to its residual value, thus making easier the control of the uncertainty element within the project.
\end{abstract}

\section{Introduction}

Real options were introduced as a complement to the information provided by the cash flow sequence presented by an investment project. In this paper, we will use the NPV model to evaluate the level of operational flexibility provided by a real option. This is a very important feature of investment projects because the information provided by a real option can modify the strategy of a company [1]. In effect, it is well known that the NPV is a static valuation method which assumes that the basic conditions of a project cannot be changed [2]. The project value may be underestimated if it is analysed only by traditional methodologies. Indeed, identifying the operational flexibility of an investment project can allow us to take advantage of the uncertainty element within the project and this can be treated as an increase in its value [3]. In effect, the ability of a company to be proactive to changes in the environment makes it possible to take advantage of some strategic opportunities and therefore to increase the value of the company.

In other words, real options are managerial tools which make easier the dynamic management of investment projects when dealing with abstract concepts [4-6]. Their use can extend the ability to make a reliable valuation of investment projects by incorporating some aspects of a strategic nature [7], since the option values represent the ability of decision makers to adapt to changing scenarios as the project progresses and new information becomes available [8].

Real options can affect several parameters of the project and can appear at any moment. Table 1 shows how each class of real options affects the value of a particular parameter.

The consideration of real options in the assessment of a project is useful both in offering an alternative approach and in providing more concrete material for calculation [9]. The use of real options involves the prior identification of the options presented in the project [10] and the subsequent determination of their value. The real options which are initially considered may help the manager to modify the project if necessary to enable a more accurate valuation to be carried out. In addition, the real option inclusion is very helpful to ensure the smooth running of the project; researches like that of Driouchi and Bennett [11] reveal that "the real option attention, knowledge and management can be more crucial for organizations than real options opportunities." 
TABLE 1: Parameters of a project and related real options. Source: own elaboration.

\begin{tabular}{lc}
\hline Parameter & Related real option \\
\hline Cash flow & To expand/to reduce \\
Residual value & To abandon \\
Duration & To defer \\
\hline
\end{tabular}

The real option approach is not widely used in business practice, despite the advice given in the academic literature to incorporate it in the assessment of a project. It is in fact normally used only by companies dealing with very large capital such us those supplying energy or healthcare, or in the technology sector. The findings of previous surveys cite the complexity of its implementation, together with lack of familiarity, as the reasons for the infrequent use of real options. Many managers consider the models used to calculate the real option value as a "black box," whose implementation requires a high degree of sophistication. This leads them to believe that any error in use may be very difficult to detect [12].

Option pricing constitutes one of the most challenging problems in computational finance and derivative modelling [13]. In order to value them, we start from the conceptual analogy with financial options which makes possible "extending the application of real option theory from the framework borrowed from financial option pricing" [14]. Although these two types of options are not of the same nature, they have many similarities. For example, in both cases, the value of an option is directly related to its maturity and to the volatility of the underlying asset.

The existing literature about real option valuation indicates two identifiable approaches, namely, discrete and continuous, depending on the complexity and nature of the analysed option [15-18]. More specifically, discrete models are more popular when valuing real options, given their simplicity [19-22]. In this paper we will use the binomial options pricing model [23], initially for one defined period, then for two periods, and, finally, for $n$ periods. And this is because the aforementioned model, used in the context of financial options appraisal, is also applicable to the case of real options $[24,25]$.

In particular, the option to abandon provides the investor with the opportunity of liquidating the entire investment project in exchange for an amount called the residual value [26]. This option can be considered as a put option which follows a multiplicative binomial pricing process [27]. Thus, the option to abandon will be exercised if the operation proves to be inefficient, that is to say, when the present value of cash flows is less than its residual value, thereby indicating the optimal time to abandon the investment [28]. These options are frequently used by venture capital companies because most of their investments are carried out in innovative sectors with a high degree of uncertainty [29]. The option to abandon increases the project value because it reduces the difficulties to terminate the project activity when it becomes a bad investment. The residual value of the project can be constant if its value has been agreed upon in a prior contract. Nevertheless, the residual value is usually variable, which makes its estimation more difficult. The residual value does not have to depend on the project value; in this case, the option to abandon has two stochastic variables which complicate its estimation: the future cash flows of the project and its residual value [30].

Therefore, the aim of this paper is to obtain a mathematical expression for the value of the option to abandon a project, terminating the business activity and liquidating assets, after one, two, and $n$ periods of time. This type of option, along with the options to extend, to reduce, and to defer, is one of the real options most used in business practice and engineering projects.

In general, the total value of an investment project can be divided into two components: the static NPV and the value of the real option [31]. "If the real option value is negligible, a traditional NPV analysis is sufficient for making a decision" [12]. Thus, the steps to be taken into account to obtain the expression of the price of the option to abandon are the following:

(i) First, the value of an investment project is calculated by including the flexibility represented by the possession of an option to abandon.

(ii) Second, it must be shown mathematically whether this value is greater than the project value without the option to abandon.

(iii) Finally, the value of the option to abandon is obtained by the difference between the values of the project when the real option is included and when it is not.

This paper is organized as follows. After this Introduction, Section 2 introduces the methodology to be used in the rest of the paper to obtain the mathematical expression of the option to abandon a project within a period. Section 3 presents the generalization of Section 2 to two periods and allows us to derive the mathematical expression for $n$ periods, shown in Section 4. Finally, Section 5 summarises and concludes.

\section{Option to Abandon within a Period}

The value of the option to abandon a project at any time prior to the expiry of the first period (denoted by $V(A B)_{0}^{(1)}$ ), using a continuous stochastic process, is given by

$$
\begin{aligned}
& V(A B)_{0}^{(1)} \\
& \quad=\frac{1}{1+r_{f}} \iint_{-\infty}^{+\infty} \max \left\{V_{1}, R V_{1}\right\} f\left(V_{1}, R V_{1}\right) d V_{1} d R V_{1},
\end{aligned}
$$

where $r_{f}$ is the riskless interest rate, $V_{1}$ represents the random variable which describes the value of the project cash flows at instant $1, R V_{1}$ denotes the stochastic residual value of the project at instant 1 , and $f\left(V_{1}, R V_{1}\right)$ is the joint probability density function of $V_{1}$ and $R V_{1}$. 
Nevertheless and for the sake of simplicity, we have opted for the use of the discrete stochastic model called the binomial options pricing model. Accordingly, starting from the present value of cash flows $\left(V_{0}\right)$ and the present value of the residual value $\left(R V_{0}\right)$, it is assumed that there are only two possible scenarios for both $V_{1}$ and $R V_{1}$ whose probabilities of occurrence are $p$ and $q=1-p$, respectively. Thus, the first scenario describes an upward movement of $V_{0}$ and $R V_{0}$ with probability $p$, whilst the second scenario represents a downward movement of $V_{0}$ and $R V_{0}$ with probability $q$. Therefore, both the value of cash flows and the residual value at instant 1 can be described by the following dichotomous random variables representing their evolution:

$$
V_{1}= \begin{cases}u V_{0}, & \text { with probability } p \\ d V_{0}, & \text { with probability } q=1-p\end{cases}
$$

where $u$ and $d$ are, respectively, the upward and downward possible movements of $V_{0}$. As previously indicated, it is assumed that the residual value is also a dichotomous random variable. This is because, according to the Gordon and Shapiro model [32], the residual value of the project at instant $n\left(R V_{n}\right)$ can be calculated as follows:

$$
R V_{n}=\frac{V_{n}(1+g)}{k-g},
$$

where $V_{n}$ is the value of cash flow at instant $n, k$ is the market discount rate, and $g$ is the cumulative increase rate of cash flows. So, the evolution of the residual value of a project can be expressed as follows:

$$
R V_{1}= \begin{cases}u^{\prime} R V_{0}, & \text { with probability } p \\ d^{\prime} R V_{0}, & \text { with probability } q=1-p,\end{cases}
$$

where $u^{\prime}$ and $d^{\prime}$ are, respectively, the upward and downward possible movements of $R V_{0}$. Thus, the project value with the option to abandon will be determined according to the factors representing the upward $(u)$ and downward $(d)$ movements applied to the present value of the future cash flows, where $u=e^{\sqrt{\sigma}}$ and $d=1 / u, \sigma$ being the volatility of the present value during one period. Analogously, the upward and downward factors concerning the residual value of the project are $u^{\prime}$ and $d^{\prime}$, respectively, where we have assumed that $d<d^{\prime}<$ $u^{\prime}<u$. That is to say, the relative range of $R V_{1}$ is less than that corresponding to $V_{1}$. This statement is in line with Mascareñas [27]: if things go well, the early abandonment of the project is not the best decision, but if they go badly it might be advisable.

By using the binomial options pricing distribution, these factors will allow us to foresee the value of the project in a favourable $\left(V^{+}\right)$or an unfavourable situation $\left(V^{-}\right)$, so that

$$
\begin{aligned}
& V^{+}=\max \left\{u V_{0}, u^{\prime} R V_{0}\right\}, \\
& V^{-}=\max \left\{d V_{0}, d^{\prime} R V_{0}\right\},
\end{aligned}
$$

whose probabilities of occurrence are $p$ and $q$, respectively. Consequently, the NPV of a project with the option to abandon within a period is given by the following expression:

$$
V(A B)_{0}^{(1)}=\frac{p V^{+}+q V^{-}}{1+r_{f}}-I_{0},
$$

where $I_{0}$ is the initial investment. As $V_{1}$ and $R V_{1}$ are random variables, the project value will depend on the relative position of the residual value with respect to the value of the cash flows both in the case of an unfavourable and a favourable evolution. Nevertheless, as the residual value under the favourable condition, $u^{\prime} R V_{0}$, is always less than the value of cash flow under the same conditions, $u V_{0}$, the value of a project with the option to abandon within a period will depend on the relative position of $V_{1}$ and $R V_{1}$ in the most unfavourable situation. So, it remains as follows:

$$
V(A B)_{0}^{(1)}= \begin{cases}V_{0}-I_{0}, & \text { if } d^{\prime} R V_{0} \leq d V_{0} \\ \frac{p u V_{0}+q d^{\prime} R V_{0}}{1+r_{f}}-I_{0}, & \text { if } d^{\prime} R V_{0}>d V_{0}\end{cases}
$$

Obviously, the expression above can also be written as follows:

$$
V(A B)_{0}^{(1)}= \begin{cases}V_{0}-I_{0}, & \text { if } R V_{0} \leq \frac{d}{d^{\prime}} V_{0} \\ \frac{p u V_{0}+q d^{\prime} R V_{0}}{1+r_{f}}-I_{0}, & \text { if } R V_{0}>\frac{d}{d^{\prime}} V_{0} .\end{cases}
$$

After analysing the project value with the option to abandon within a period, we will proceed to the mathematical proof that its value is greater than or equal to the value of the project without this option. Our final objective is to obtain the value of the option to abandon.

Proposition 1. The net present value of an investment project with the option to abandon within a period is always greater than or equal to $V_{0}-I_{0}$.

Proof. In effect, we are going to consider the following two cases:

(1) If $R V_{0} \leq\left(d / d^{\prime}\right) V_{0}$, the net present value of the investment project with the option to abandon within a period is

$$
V(A B)_{0}^{(1)}=\frac{p u V_{0}+q d V_{0}}{1+r_{f}}-I_{0}=V_{0}-I_{0},
$$

which confirms the expected equality/inequality.

(2) If $R V_{0}>\left(d / d^{\prime}\right) V_{0}$, the net present value of the investment project with the option to abandon within a period is

$$
V(A B)_{0}^{(1)}=\frac{p u V_{0}+q d^{\prime} R V_{0}}{1+r_{f}}-I_{0} .
$$


Since $d V_{0}<d^{\prime} R V_{0}$, this gives

$$
V(A B)_{0}^{(1)}>V_{0}-I_{0} \text {. }
$$

To summarise, the possible results for the net present value of a project with the option to abandon within a period are as follows:

(i) If $R V_{0} \leq\left(d / d^{\prime}\right) V_{0}$, the net present value of the cash flows generated by the project is greater than the residual value in all cases. Thus, the option to abandon is not exercised since the best alternative is to continue with the business activity. Therefore, the value of the option is zero and then the net present value of the project is equal to $V_{0}-I_{0}$.

(ii) Contrarily, if $R V_{0}>\left(d / d^{\prime}\right) V_{0}$, the residual value of the project will be located between the values of the generated cash flow in the case of a favourable $\left(u V_{0}\right)$ and an unfavourable evolution $\left(d V_{0}\right)$. So, in this case, the value of the option to abandon is positive.

Hereinafter we are going to plot graphically the net present value of a project and the value of the option to abandon, for each of the studied maturities. To do this, we present the following information about the investment project.

Example 2. XHMobile is a mobile phone company which was established in 2011 and currently operates at national level. XHMobile managers are considering the expansion of the business into a foreign market with a view to increasing its turnover. In order to analyse the project the following numerical information has been taken into account [27]:

(i) To carry out the project the initial investment required $\left(I_{0}\right)$ is 104 million euros.

(ii) The present value of expected cash flows $\left(V_{0}\right)$ is estimated in 100 million euros.

(iii) The riskless discount rate $\left(r_{f}\right)$ is equal to $5 \%$.

(iv) Upward and downward factors affecting cash flows are $u=1.8$ and $d=0.56$, respectively. It is well known that the risk-neutral probabilities can be calculated starting from the following expression [33]:

$$
p=\frac{\left(1+r_{f}\right)-d}{u-d},
$$

from where $p=39.5 \%$ and $q=1-p=60.5 \%$.

(v) Upward and downward factors affecting the residual value are $u^{\prime}=1.5$ and $d^{\prime}=0.9$, respectively.

Thus, the value of the project with the option to abandon within a period is

$$
V(A B)_{0}^{(1)}= \begin{cases}-4, & \text { if } R V_{0} \leq 62.22 \\ 0.5186 R V_{0}-36.29, & \text { if } R V_{0}>62.22\end{cases}
$$

whose graphic representation can be seen in Figure 1.

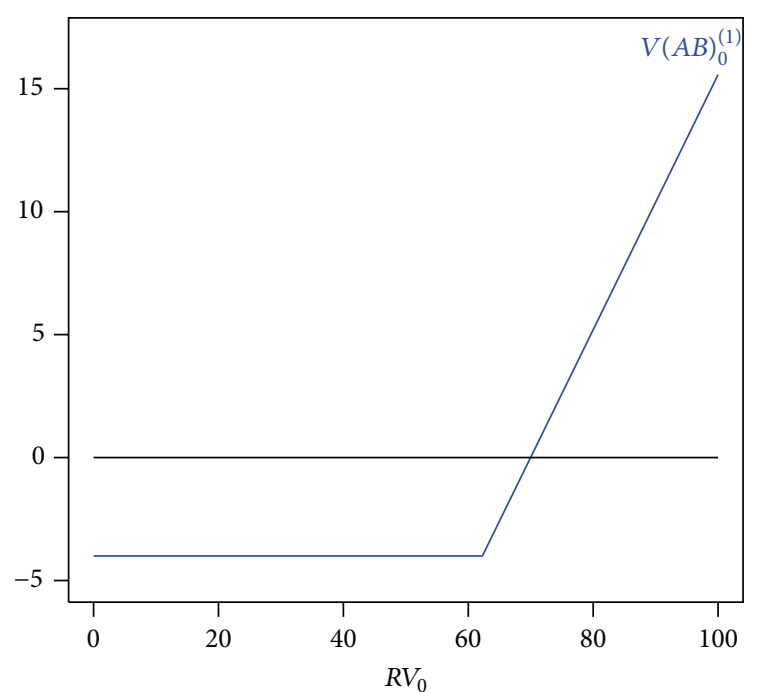

FIGURE 1: Project value with the option to abandon within a period. Source: own elaboration.

Finally, we are going to derive the value of the option to abandon a project within a period (denoted by $O_{A B}^{(1)}$ ).

Corollary 3. The value of the option to abandon an investment project after one period is

$$
O_{A B}^{(1)}= \begin{cases}0, & \text { if } R V_{0} \leq \frac{d}{d^{\prime}} V_{0} \\ \frac{q\left(d^{\prime} R V_{0}-d V_{0}\right)}{1+r_{f}}, & \text { if } R V_{0}>\frac{d}{d^{\prime}} V_{0} .\end{cases}
$$

Proof. The proof of the first case is obvious whilst, in the second case, if $R V_{0}>\left(d / d^{\prime}\right) V_{0}$, the value of the option to abandon can be calculated as follows:

$$
O_{A B}^{(1)}:=V(A B)_{0}^{(1)}-\left(V_{0}-I_{0}\right) .
$$

Therefore,

$$
O_{A B}^{(1)}=\frac{p u V_{0}+q d^{\prime} R V_{0}}{1+r_{f}}-I_{0}-\left(\frac{p u V_{0}+q d V_{0}}{1+r_{f}}-I_{0}\right),
$$

which can be simplified as follows:

$$
O_{A B}^{(1)}=\frac{q\left(d^{\prime} R V_{0}-d V_{0}\right)}{1+r_{f}} .
$$

Example 4. In Example 2, the value of the option to abandon is

$$
O_{A B}^{(1)}= \begin{cases}0, & \text { if } R V_{0} \leq 62.22 \\ 0.5186 R V_{0}-32.29, & \text { if } R V_{0}>62.22\end{cases}
$$

whose graphic representation can be seen in Figure 2. 


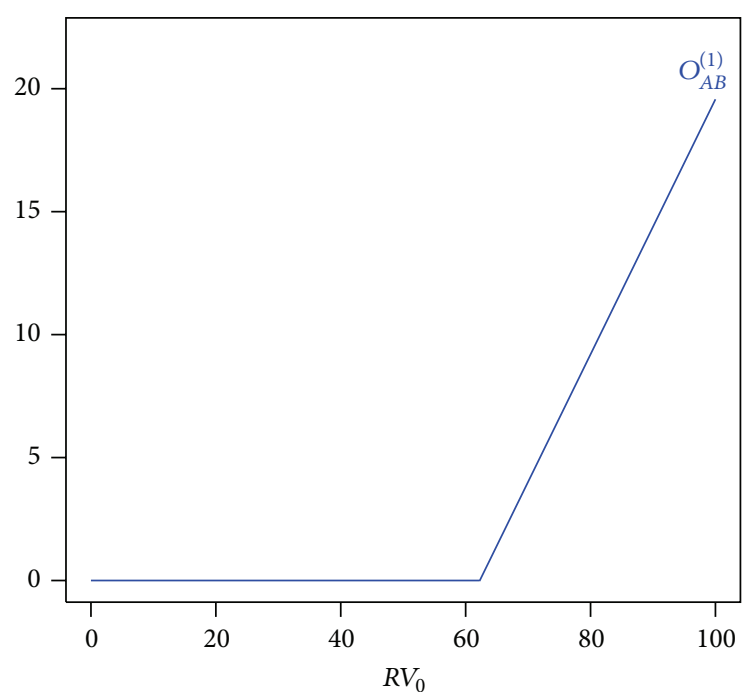

FIGURE 2: Value of the option to abandon within a period. Source: own elaboration.

\section{Option to Abandon within Two Periods}

The present value of an investment project with the option to abandon after two periods, denoted by $V(A B)_{0}^{(2)}$, will depend on the evolution of cash flows and the residual value of the project during these two periods. Figure 3 schematically represents the evolution of the initial investment, the cash flows, and the residual values for two periods following the aforementioned binomial options pricing model.

In this way, the possible project values after two periods are given by the following expressions:

$$
\begin{aligned}
& V^{++}=\max \left\{u^{2} V_{0}, u^{\prime 2} R V_{0}\right\}, \\
& V^{+-}=\max \left\{u d V_{0}, u^{\prime} d^{\prime} R V_{0}\right\}, \\
& V^{--}=\max \left\{d^{2} V_{0}, d^{\prime 2} R V_{0}\right\},
\end{aligned}
$$

where their probabilities of occurrence are $p^{2}, 2 p q$, and $q^{2}$, respectively. Therefore, the project value with the option to abandon has the following expression:

$$
V(A B)_{0}^{2}=\frac{p^{2} V^{++}+2 p q V^{+-}+q^{2} V^{--}}{\left(1+r_{f}\right)^{2}}-I_{0} .
$$

Thus, taking into account all possible cases describing the relative position of $R V_{0}$ with respect to $V_{0}$, one has

$$
V(A B)_{0}^{(2)}= \begin{cases}\frac{p_{0}-I_{0},}{u^{2} V_{0}+2 p q u d V_{0}+q^{2} d^{\prime 2} R V_{0}}-I_{0}, & \text { if } R V_{0} \leq \frac{d^{2}}{d^{\prime 2}} V_{0} \\ \left(1+r_{f}\right)^{2} & \text { if } \frac{d^{2}}{d^{\prime 2}} V_{0}<R V_{0} \leq \frac{u d}{u^{\prime} d^{\prime}} V_{0} \\ \frac{p^{2} u^{2} V_{0}+2 p q u^{\prime} d^{\prime} R V_{0}+q^{2} d^{\prime 2} R V_{0}}{\left(1+r_{f}\right)^{2}}-I_{0}, & \text { if } R V_{0}>\frac{u d}{u^{\prime} d^{\prime}} V_{0} .\end{cases}
$$

The next step is to demonstrate mathematically whether the present value of the investment project with the option to abandon within two periods is greater than or equal to

(i) the project value with the option to abandon within a period and

(ii) the project value without this option.

Our final objective is to obtain the value of the option to abandon a project after two periods from the present. But first we are going to enunciate the following result which will be needed for another statement to be proved.

Lemma 5. If the market discount rate $(k)$ is less than $1+r_{f}$, then $p u^{\prime}+q d^{\prime}>1+r_{f}$.

Proof. Let us start from expression (3) of $R V_{n}$. In this paper, the increase rate of the present value is $r_{f}$, so, we can write

$$
R V_{n}=\frac{V_{n}\left(1+r_{f}\right)}{k-r_{f}}
$$

On the other hand, as

$$
\begin{gathered}
E\left(R V_{n}\right)=\left(p u^{\prime}+q d^{\prime}\right)^{n} R V_{0}, \\
E\left(V_{n}\right)=\left(1+r_{f}\right)^{n} V_{0},
\end{gathered}
$$

we can write

$$
\left(p u^{\prime}+q d^{\prime}\right)^{n} R V_{0}=\frac{\left(1+r_{f}\right)^{n} V_{0}\left(1+r_{f}\right)}{k-r_{f}},
$$

from where

$$
\left(k-r_{f}\right)\left(p u^{\prime}+q d^{\prime}\right)^{n} R V_{0}=\left(1+r_{f}\right)^{n} V_{0}\left(1+r_{f}\right) .
$$

As $R V_{0}<V_{0}$ (otherwise, the company would have chosen not to undertake the project [27]) and $k-r_{f}<1+r_{f}$, we can deduce that

$$
p u^{\prime}+q d^{\prime}>1+r_{f}
$$




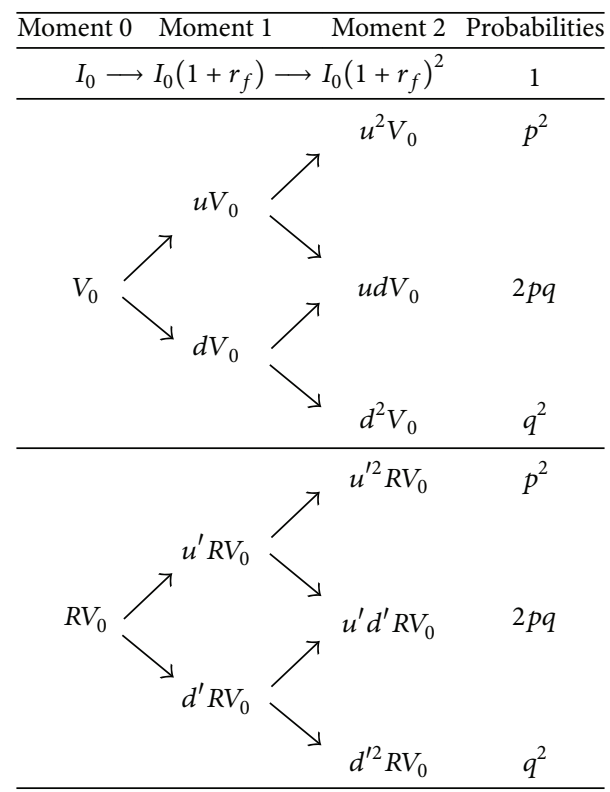

FIgURE 3: Evolution of the initial payment, cash flows, and residual values over a period of two years. Source: own elaboration.

\begin{tabular}{|c|l|c|}
\hline \multicolumn{2}{|c|}{$R V_{0} \leq \frac{d}{d^{\prime}} V_{0}\left(I_{11}\right)$} & \multicolumn{2}{|c|}{$R V_{0}>\frac{d}{d^{\prime}} V_{0}\left(I_{12}\right)$} \\
\hline$R V_{0} \leq \frac{d^{2}}{d^{\prime 2}} V_{0}\left(I_{21}\right)$ & $\frac{d^{2}}{d^{\prime 2}} V_{0}<R V_{0} \leq \frac{u d}{u^{\prime} d^{\prime}} V_{0}\left(I_{22}\right)$ & $R V_{0}>\frac{u d}{u^{\prime} d^{\prime}} V_{0}\left(I_{23}\right)$ \\
\hline
\end{tabular}

Figure 4: Possible intervals for $V R_{0}$ according to expressions $V(A B)_{0}^{(1)}$ and $V(A B)_{0}^{(2)}$. Source: own elaboration.

Hereinafter, we are going to suppose that the logical hypothesis of Lemma 5 about the market discount rate always holds. Now, we can deduce the following statement.

Proposition 6. $V(A B)_{0}^{(2)} \geq V(A B)_{0}^{(1)} \geq V_{0}-I_{0}$.

Proof. For a better understanding of this demonstration, Figure 4 shows the possible intervals to which $R V_{0}$ can belong according to the different intervals defining $V(A B)_{0}^{(1)}$ and $V(A B)_{0}^{(2)}$. Therefore, we have distinguished between the intervals of $R V_{0}$ corresponding to the option to abandon within a period (indicated in blue) and the option to abandon within two periods (indicated in orange).

To understand the meaning of Figure 4, we must clarify that if $R V_{0}$ belongs to some interval of period 2 then it belongs to the intervals of period 1 located in the adjacent cells immediately above. In effect, the following hold:

(1) If $R V_{0} \leq\left(d^{2} / d^{\prime 2}\right) V_{0}$, since $d / d^{\prime}<1$, it can immediately be deduced that $R V_{0} \leq\left(d^{2} / d^{\prime 2}\right) V_{0}<$ $\left(d / d^{\prime}\right) V_{0}$. Therefore, as expected, $I_{21} \subseteq I_{11}$.

(2) If $\left(d^{2} / d^{\prime 2}\right) V_{0}<R V_{0} \leq\left(u d / u^{\prime} d^{\prime}\right) V_{0}$, a priori there could be any relationship of inequality between $R V_{0}$ and $\left(d / d^{\prime}\right) V_{0}$. Therefore, $I_{22} \subseteq I_{11} \cup I_{12}$.
(3) Finally, if $\left(u d / u^{\prime} d^{\prime}\right) V_{0}<R V_{0}$, then $\left(d / d^{\prime}\right) V_{0}<$ $\left(u d / u^{\prime} d^{\prime}\right) V_{0}<R V_{0}$ because $\left(u / u^{\prime}\right)>1$. Hence, $I_{23} \subseteq$ $I_{12}$.

Once the implications schematized in Figure 4 have been shown, we will demonstrate the statement of this proposition. In effect, the following hold:

(1) If $R V_{0} \leq\left(d^{2} / d^{\prime 2}\right) V_{0}$, the project value is not affected by the option to abandon and therefore (remember that $I_{21} \subseteq I_{11}$ )

$$
V(A B)_{0}^{(2)}=V_{0}-I_{0}=V(A B)_{0}^{(1)},
$$

which is the expected equality/inequality.

(2) If $\left(d^{2} / d^{\prime 2}\right) V_{0}<R V_{0} \leq\left(u d / u^{\prime} d^{\prime}\right) V_{0}$, the present value of the investment project with the option to abandon within two periods is

$V(A B)_{0}^{(2)}=\frac{p^{2} u^{2} V_{0}+2 p q u d V_{0}+q^{2} d^{\prime 2} R V_{0}}{\left(1+r_{f}\right)^{2}}-I_{0}$.

Now we are going to compare this value with the project value without the option to abandon, $V_{0}-I_{0}$, which coincides with the project value with the option to abandon within a period when $R V_{0} \leq\left(d / d^{\prime}\right) V_{0}$. Moreover, we can write

$V_{0}-I_{0}=\frac{p^{2} u^{2} V_{0}+2 p q u d V_{0}+q^{2} d^{2} V_{0}}{\left(1+r_{f}\right)^{2}}-I_{0}$.

Hence, since $d^{2} V_{0}<d^{\prime 2} R V_{0}$, the following inequality holds:

$$
V(A B)_{0}^{(2)}>V_{0}-I_{0}=V(A B)_{0}^{(1)} .
$$

Thus, it remains to compare the project value including the option to abandon within a period when $R V_{0}>\left(d / d^{\prime}\right) V_{0}$ :

$$
V(A B)_{0}^{(1)}=\frac{p u V_{0}+q d^{\prime} R V_{0}}{1+r_{f}}-I_{0}
$$

with the project value including the option to abandon within two periods. To do this, we will take into account that

$$
\frac{p u}{1+r_{f}}=1-\frac{q d}{1+r_{f}}
$$

and that, from Lemma 5,

$$
\frac{q d^{\prime}}{1+r_{f}}>1-\frac{p u^{\prime}}{1+r_{f}} \text {. }
$$


In this case,

$$
\begin{aligned}
V(A B)_{0}^{(2)}= & \frac{p^{2} u^{2} V_{0}+2 p q u d V_{0}+q^{2} d^{\prime 2} R V_{0}}{\left(1+r_{f}\right)^{2}}-I_{0} \\
> & \frac{p u V_{0}}{1+r_{f}}-\frac{p q u d V_{0}}{\left(1+r_{f}\right)^{2}}+\frac{2 p q u d V_{0}}{\left(1+r_{f}\right)^{2}} \\
& +\frac{q d^{\prime} R V_{0}}{1+r_{f}}-\frac{p q u^{\prime} d^{\prime} R V_{0}}{\left(1+r_{f}\right)^{2}}-I_{0} \\
= & \frac{p u V_{0}}{1+r_{f}}+\frac{p q u d V_{0}}{\left(1+r_{f}\right)^{2}}+\frac{q d^{\prime} R V_{0}}{1+r_{f}} \\
& -\frac{p q u^{\prime} d^{\prime} R V_{0}}{\left(1+r_{f}\right)^{2}}-I_{0} \\
> & \frac{p u V_{0}+q d^{\prime} R V_{0}}{1+r_{f}}-I_{0}=V(A B)_{0}^{(1)},
\end{aligned}
$$

since $u^{\prime} d^{\prime} R V_{0} \leq u d V_{0}$. Therefore, the expected equality/inequality holds.

(3) Finally, if $R V_{0}>\left(u d / u^{\prime} d^{\prime}\right) V_{0}$, the present value of the investment project with the option to abandon within two periods is

$$
V(A B)_{0}^{(2)}=\frac{p^{2} u^{2} V_{0}+2 p q u^{\prime} d^{\prime} R V_{0}+q^{2} d^{\prime} R V_{0}}{\left(1+r_{f}\right)^{2}}-I_{0} .
$$

Taking into account that $V_{0}-I_{0}=\left(p^{2} u^{2} V_{0}+\right.$ $\left.2 p q u d V_{0}+q^{2} d^{2} V_{0}\right) /\left(1+r_{f}\right)^{2}-I_{0}$, it can be easily shown that

$$
V(A B)_{0}^{(2)}>V_{0}-I_{0}
$$

since $u^{\prime} d^{\prime} R V_{0}>u d V_{0}$ which moreover implies that $d^{\prime 2} R V_{0}>d^{2} V_{0}$. Therefore, we have just shown that the project value including the option to abandon within two periods is greater than or equal to the project value without such an option. Thus, the next step consists in comparing the project value with the option to abandon within two periods and its value including the option to abandon within one period. To do this, we will consider again (32) and (33) which lead to

$$
\begin{aligned}
V(A B)_{0}^{(2)}= & \frac{p^{2} u^{2} V_{0}+2 p q u^{\prime} d^{\prime} R V_{0}+q d^{\prime 2} R V_{0}}{\left(1+r_{f}\right)^{2}}-I_{0} \\
>> & \frac{p u V_{0}}{1+r_{f}}-\frac{p q u d V_{0}}{\left(1+r_{f}\right)^{2}}+\frac{2 p q u^{\prime} d^{\prime} R V_{0}}{\left(1+r_{f}\right)^{2}} \\
& +\frac{q d^{\prime} R V_{0}}{1+r_{f}}-\frac{p q u^{\prime} d^{\prime} R V_{0}}{\left(1+r_{f}\right)^{2}}-I_{0} \\
= & \frac{p u V_{0}}{1+r_{f}}-\frac{p q u d V_{0}}{\left(1+r_{f}\right)^{2}}+\frac{p q u^{\prime} d^{\prime} R V_{0}}{\left(1+r_{f}\right)^{2}} \\
& +\frac{q d^{\prime} R V_{0}}{1+r_{f}}-I_{0}>\frac{p u V_{0}+q d^{\prime} R V_{0}}{1+r_{f}}-I_{0} \\
= & V(A B)_{0}^{(1)},
\end{aligned}
$$

since $u^{\prime} d^{\prime} R V_{0}>u d V_{0}$, which shows the expected inequality.

Example 7. In Example 2, the project value of the mobile phone company with the option to abandon within two periods is

$$
\begin{aligned}
& V(A B)_{0}^{(2)} \\
& = \begin{cases}-4, & \text { if } R V_{0} \leq 38.72 \\
0.2689 R V_{0}-14.46, & \text { if } 38.72<R V_{0} \leq 74.67 \\
0.8542 R V_{0}-58.15, & \text { if } R V_{0}>74.67\end{cases}
\end{aligned}
$$

whose graphic representation can be seen in Figure 5 (indicated in green).

Corollary 8. The value of the option to abandon the project after two periods, denoted by $\mathrm{O}_{A B}^{(2)}$, is

$$
O_{A B}^{(2)}= \begin{cases}\frac{q^{2}\left(d^{\prime 2} R V_{0}-d^{2} V_{0}\right)}{\left(1+r_{f}\right)^{2}}, & \text { if } R V_{0} \leq \frac{d^{2}}{d^{\prime 2}} V_{0} \\ \frac{2 p q\left(u^{\prime} d^{\prime} R V_{0}-u d V_{0}\right)+q^{2}\left(d^{\prime 2} R V_{0}-d^{2} V_{0}\right)}{\left(1+r_{f}\right)^{2}}, & \text { if } \frac{d^{2}}{d^{\prime 2}} V_{0}<R V_{0} \leq \frac{u d}{u^{\prime} d^{\prime}} V_{0} \\ & \text { if } R V_{0}>\frac{u d}{u^{\prime} d^{\prime}} V_{0} .\end{cases}
$$




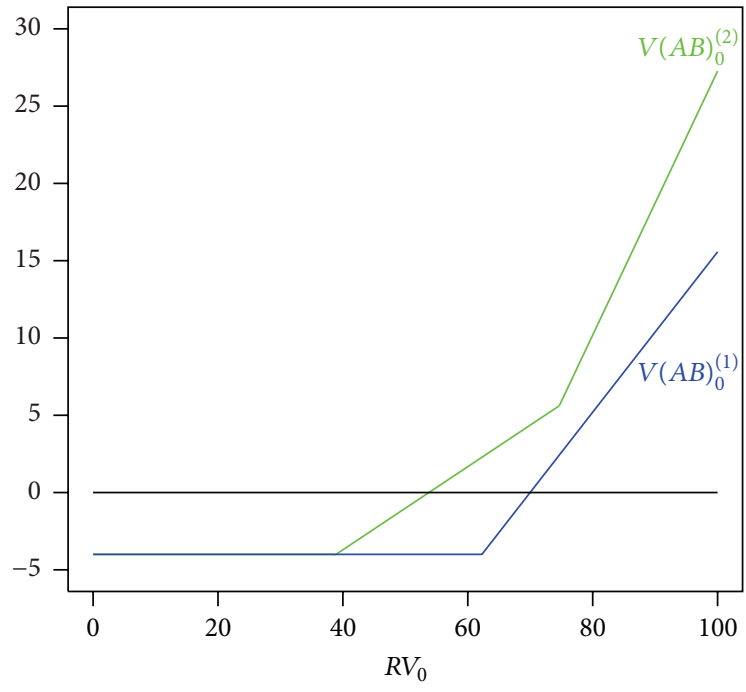

FIgURE 5: Project value with the option to abandon within one and two periods. Source: own elaboration.

Proof. In effect, the value of the option to abandon the project within two periods can be calculated as the difference between the project values with the option, $V(A B)_{0}^{(2)}$, and without it, $V_{0}-I_{0}$; namely,

$$
O_{A B}^{(2)}:=V(A B)_{0}^{(2)}-\left(V_{0}-I_{0}\right) .
$$

Thus, in order to ascertain more the value of $O_{A B}^{(2)}$, we have to take into account the three possible expressions for $V(A B)_{0}^{(2)}$. In the first case, the proof is obvious. However, we present the following calculations for the second and third cases:

(1) If $\left(d^{2} / d^{\prime 2}\right) V_{0}<R V_{0} \leq\left(u d / u^{\prime} d^{\prime}\right) V_{0}$, the option value can be calculated as follows:

$$
\begin{aligned}
O_{A B}^{(2)}= & \frac{p^{2} u^{2} V_{0}+2 p q u d V_{0}+q^{2} d^{\prime 2} R V_{0}}{\left(1+r_{f}\right)^{2}}-I_{0} \\
& -\left(\frac{p^{2} u^{2} V_{0}+2 p q u d V_{0}+q^{2} d^{2} V_{0}}{\left(1+r_{f}\right)^{2}}-I_{0}\right),
\end{aligned}
$$

which, once simplified, remains as

$$
O_{A B}^{(2)}=\frac{q^{2}\left(d^{\prime 2} R V_{0}-d^{2} V_{0}\right)}{\left(1+r_{f}\right)^{2}} .
$$

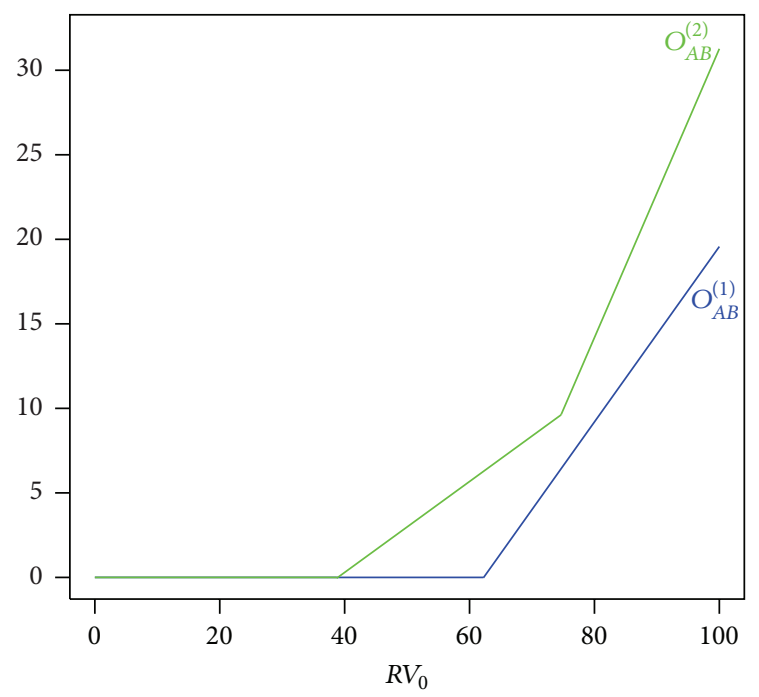

FIGURE 6: Option value to abandon within one and two periods. Source: own elaboration.

(2) If $R V_{0}>\left(u d / u^{\prime} d^{\prime}\right) V_{0}$, the expression of the option to abandon within two periods is the following:

$$
\begin{aligned}
O_{A B}^{(2)}= & \frac{p^{2} u^{2} V_{0}+2 p q u^{\prime} d^{\prime} R V_{0}+q^{2} d^{\prime 2} R V_{0}}{\left(1+r_{f}\right)^{2}}-I_{0} \\
& -\left(\frac{p^{2} u^{2} V_{0}+2 p q u d V_{0}+q^{2} d^{2} V_{0}}{\left(1+r_{f}\right)^{2}}-I_{0}\right) \\
= & \frac{2 p q\left(u^{\prime} d^{\prime} R V_{0}-u d V_{0}\right)+q^{2}\left(d^{\prime 2} R V_{0}-d^{2} V_{0}\right)}{\left(1+r_{f}\right)^{2}} .
\end{aligned}
$$

Example 9. In Example 2, the option value of the mobile phone company to abandon within two periods is

$$
\begin{aligned}
& O_{A B}^{(2)} \\
& = \begin{cases}0, & \text { if } R V_{0} \leq 38.72 \\
0.2689 R V_{0}-10.46, & \text { if } 38.72<R V_{0} \leq 74.67 \\
0.8542 R V_{0}-54.15, & \text { if } R V_{0}>74.67\end{cases}
\end{aligned}
$$

whose graphic representation can be seen in Figure 6 (indicated in green). 


\section{Option to Abandon within $n$ Periods}

In this section, we are going to determine the general mathematical expression for the present value of an investment project which includes the option to abandon within $n$ periods, denoted by $V(A B)_{0}^{(n)}$, and the value of this option, denoted by $O_{A B}^{(n)}$. In order to calculate $V(A B)_{0}^{(n)}$, we are going to consider the following $n+1$ possible intervals for $R V_{0}$ :

$$
\begin{gathered}
R V_{0} \leq \frac{d^{n}}{d^{\prime n}} V_{0}, \quad \text { denoted by } I_{n, 0} . \\
\frac{u^{k-1} d^{n-k+1}}{u^{\prime k-1} d^{\prime n-k+1}} V_{0}<R V_{0} \leq \frac{u^{k} d^{n-k}}{u^{\prime k} d^{\prime n-k}} V_{0} \\
k=1,2, \ldots, n-1, \text { denoted respectively by } I_{n, k} . \\
R V_{0}>\frac{u^{n-1} d}{u^{\prime n-1} d^{\prime}} V_{0}, \text { denoted by } I_{n, n} .
\end{gathered}
$$

Observe that all these intervals are consecutive and disjoint and have increasing left and right endpoints. Moreover, as $u / u^{\prime}>d / d^{\prime}$, they are well defined. So, if $R V_{0} \in I_{n, k}$, $k=0,1, \ldots, n$, then $R V_{0}$ is greater than the left endpoints of $I_{n, 0}, I_{n, 1}, \ldots, I_{n, k}$ and $R V_{0}$ is less than the right endpoints of $I_{n, k}, I_{n, k+1}, \ldots, I_{n, n}$. Observe that there can be a value of $k$ such that $u^{k} d^{n-k} / u^{\prime k} d^{\prime n-k}>1$. In such a case, the last interval for $R V_{0}$ will be $u^{k-1} d^{n-k+1} / u^{\prime k-1} d^{\prime n-k+1} V_{0}<R V_{0} \leq$ $V_{0}$ because, as indicated in Lemma 5, the inequality $R V_{0}>V_{0}$ does not make sense. Therefore, the mathematical expression of $V(A B)_{0}^{(n)}$ for the $k$ th interval for $R V_{0}(k=1,2, \ldots, n)$ is the following:

$$
\begin{aligned}
& V(A B)_{0}^{(n)}=\frac{1}{\left(1+r_{f}\right)^{n}}\left[V_{0} \sum_{i=0}^{n-k}\left(\begin{array}{l}
n \\
i
\end{array}\right)(p u)^{n-i}(q d)^{i}\right. \\
& \left.+R V_{0} \sum_{i=n-k+1}^{n}\left(\begin{array}{c}
n \\
i
\end{array}\right)\left(p u^{\prime}\right)^{n-i}\left(q d^{\prime}\right)^{i}\right]-I_{0} .
\end{aligned}
$$

Now, we are going to obtain a more simplified expression which will be useful to determine later the mathematical expression of the option to abandon the project after $n$ periods. In effect, we can write

$$
\begin{aligned}
& V(A B)_{0}^{(n)}=V_{0} \\
& -\frac{1}{\left(1+r_{f}\right)^{n}}\left[V_{0} \sum_{i=n-k+1}^{n}\left(\begin{array}{c}
n \\
i
\end{array}\right)(p u)^{n-i}(q d)^{i}\right. \\
& \left.-R V_{0} \sum_{i=n-k+1}^{n}\left(\begin{array}{c}
n \\
i
\end{array}\right)\left(p u^{\prime}\right)^{n-i}\left(q d^{\prime}\right)^{i}\right]-I_{0}=V_{0} \\
& +\frac{1}{\left(1+r_{f}\right)^{n}} \sum_{i=n-k+1}^{n}\left(\begin{array}{c}
n \\
i
\end{array}\right) p^{n-i} q^{i}\left(u^{\prime n-i} d^{\prime i} R V_{0}\right. \\
& \left.-u^{n-i} d^{i} V_{0}\right)-I_{0} .
\end{aligned}
$$

Consequently, the extended expression of $V(A B)_{0}^{(n)}$ is

$$
V(A B)_{0}^{(n)}= \begin{cases}V_{0}-I_{0}, & \text { if } R V_{0} \leq \frac{d^{n}}{d^{\prime n}} V_{0} \\
V_{0}+\frac{q^{n}\left(d^{\prime n} R V_{0}-d^{n} V_{0}\right)}{\left(1+r_{f}\right)^{n}}-I_{0}, & \text { if } \frac{d^{n}}{d^{\prime n}} V_{0}<R V_{0} \leq \frac{u d^{n-1}}{u^{\prime} d^{\prime n-1}} V_{0} \\
V_{0}+\frac{n p q^{n-1}\left(u^{\prime} d^{\prime n-1} R V_{0}-u d^{n-1} V_{0}\right)+q^{n}\left(d^{\prime n} R V_{0}-d^{n} V_{0}\right)}{\left(1+r_{f}\right)^{n}}-I_{0}, & \text { if } \frac{u d^{n-1}}{u^{\prime} d^{\prime n-1}} V_{0}<R V_{0} \leq \frac{u^{2} d^{n-2}}{u^{\prime 2} d^{\prime n-2}} V_{0} \\
\vdots & \vdots \\
V_{0}+\frac{1}{\left(1+r_{f}\right)^{n}} \sum_{i=1}^{n}\left(\begin{array}{c}
n \\
i
\end{array}\right) p^{n-i} q^{i}\left(u^{\prime n-i} d^{\prime i} R V_{0}-u^{n-i} d^{i} V_{0}\right)-I_{0}, & \text { if } R V_{0}>\frac{u^{n-1} d}{u^{\prime n-1} d^{\prime}} V_{0} .\end{cases}
$$

It is easy to observe that $V(A B)_{0}^{(n)}$ is increasing by intervals and that, using reasoning similar to the proof of Proposition 6, we can show that

$$
V(A B)_{0}^{(n)} \geq V(A B)_{0}^{(n-1)} \geq \cdots \geq V(A B)_{0}^{(1)} \geq V_{0}-I_{0}
$$

Example 10. In Example 2, the project value of the mobile phone company with the option to abandon within five periods is

$$
\begin{aligned}
& V(A B)_{0}^{(5)} \\
& = \begin{cases}-4, & \text { if } R V_{0} \leq 9.33 \\
0.0375 R V_{0}-4.35, & \text { if } 9.33<R V_{0} \leq 17.99 \\
0.2415 R V_{0}-8.02, & \text { if } 17.99<R V_{0} \leq 34.69 \\
0.6856 R V_{0}-23.42, & \text { if } 34.69<R V_{0} \leq 66.90 \\
1.1688 R V_{0}-55.75, & \text { if } R V_{0}>66.90\end{cases}
\end{aligned}
$$




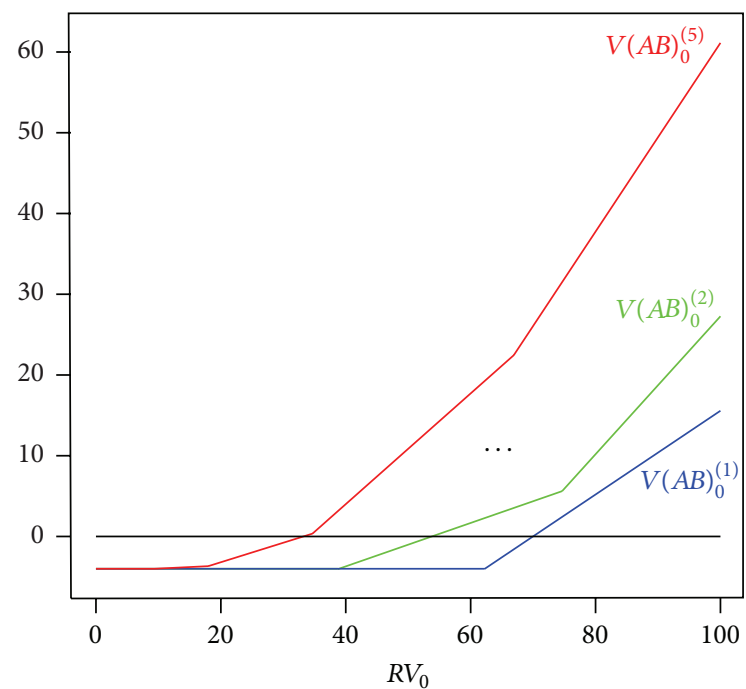

FIgURE 7: Project value with the option to abandon within one, two, and five periods. Source: own elaboration. whose graphic representation can be seen in Figure 7 (indicated in red).

Finally, the mathematical expression of $O_{A B}^{(n)}$ is

$$
\begin{aligned}
& O_{A B}^{(n)}=V(A B)_{0}^{(n)}-\left(V_{0}-I_{0}\right)=\frac{1}{\left(1+r_{f}\right)^{n}} \\
& \cdot \sum_{i=n-k+1}^{n}\left(\begin{array}{c}
n \\
i
\end{array}\right) p^{n-i} q^{i}\left(u^{\prime n-i} d^{\prime i} R V_{0}-u^{n-i} d^{i} V_{0}\right) .
\end{aligned}
$$

Consequently, the extended expression of $O_{A B}^{(n)}$ is

$$
O_{A B}^{(n)}= \begin{cases}0, & \text { if } R V_{0} \leq \frac{d^{n}}{d^{\prime n}} V_{0} \\
\frac{q^{n}\left(d^{\prime n} R V_{0}-d^{n} V_{0}\right)}{\left(1+r_{f}\right)^{n}}, & \text { if } \frac{d^{n}}{d^{\prime n}} V_{0}<R q_{0} \leq \frac{u d^{n-1}}{u^{\prime} d^{\prime n-1}\left(u^{\prime} d^{\prime n-1} R V_{0}-u d^{n-1} V_{0}\right)+q^{n}\left(d^{\prime n} R V_{0}-d^{n} V_{0}\right)} \\
\left(1+r_{f}\right)^{n} & \text { if } \frac{u^{k-1} d^{n-k+1}}{u^{\prime k-1} d^{\prime n-k-1}} V_{0}<R V_{0} \leq \frac{u^{k} d^{n-k}}{u^{\prime k} d^{\prime n-1}} V_{0} \\
\frac{1}{\left(1+r_{f}\right)^{n}} \sum_{i=1}^{n}\left(\begin{array}{c}
n \\
i
\end{array}\right) p^{n-i} q^{i}\left(u^{\prime n-i} d^{\prime i} R V_{0}-u^{n-i} d^{i} V_{0}\right), & \vdots\end{cases}
$$

Example 11. In Example 2, the option value of the mobile phone company to abandon within five periods is

$$
\begin{aligned}
& O_{A B}^{(5)} \\
& = \begin{cases}0, & \text { if } R V_{0} \leq 9.33 \\
0.0375 R V_{0}-0.35, & \text { if } 9.33<R V_{0} \leq 17.99 \\
0.2415 R V_{0}-4.02, & \text { if } 17.99<R V_{0} \leq 34.69 \\
0.6856 R V_{0}-19.42, & \text { if } 34.69<R V_{0} \leq 66.90 \\
1.1688 R V_{0}-51.75, & \text { if } R V_{0}>66.90\end{cases}
\end{aligned}
$$

whose graphic representation can be seen in Figure 8 (indicated in red).

\section{Conclusion}

Real options constitute an important part of project assessment; they provide a means to assess the value of flexibility in business operations. Given the limited use of the methodologies to quantify real options in business practice, as a result of their high degree of sophistication, this paper aims to provide a simple formula to quantify the value of one of the types of real options most common in practice: the option to abandon.

Obviously, the right to exercise the option to abandon allows the sale of the project in exchange for its residual value, since this operation is similar to a put option. In this way, the methodology employed to develop the expression to obtain the value of the option to abandon is based on the implementation of the binomial options pricing model. The procedure consists in an accurate reconstruction of all possible future scenarios with their respective probabilities of occurrence. This analysis has been initially performed for options to abandon whose maturity is within one period. In the next step, we deduce the expression of those options whose expiry is within two periods and, finally, the corresponding expression for options expiring within $n$ periods is obtained.

The main contribution of this paper is the introduction of the mathematical expression, complementary to the net present value expression, in order to quantify in an intuitive way the value of a project including the option to abandon within a given period. Its use contributes to a more accurate 


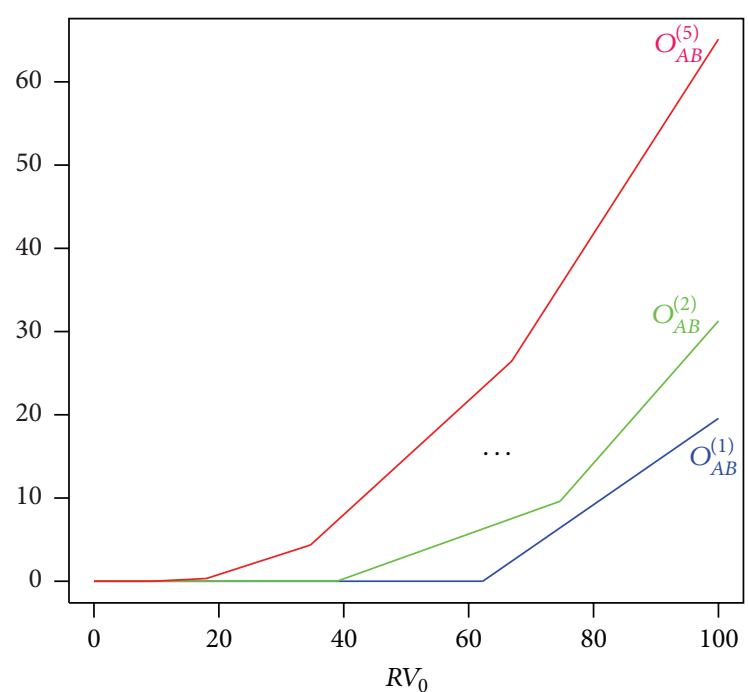

FIGURE 8: Option value to abandon within one, two, and five periods. Source: own elaboration.

assessment, thus giving more control over the element of uncertainty.

In all cases, it has been shown that the option value to abandon is greater than or equal to zero and that, as the maturity of the option increases, its value also increases. This analysis has been completed with the graphic representation of the value of the project and the option in every one of the expiry periods considered (one, two, and $n$ periods), using a numerical example.

\section{Conflict of Interests}

The authors declare that there is no conflict of interests regarding the publication of this paper.

\section{Acknowledgment}

The authors are very grateful for the comments and suggestions made by an anonymous referee.

\section{References}

[1] S. C. Myers, "Determinants of corporate borrowing," Journal of Financial Economics, vol. 5, no. 2, pp. 147-175, 1977.

[2] A. M. Calle Fernández and V. M. Tamayo Bustamante, "Decisiones de inversión a través de opciones reales," Estudios Gerenciales, vol. 25, no. 111, pp. 107-126, 2009.

[3] A. K. Dixit and R. S. Pindyck, "The options approach to capital investment," Harvard Business Review, vol. 73, pp. 105-115, 1995.

[4] W. C. Kester, “Today's options for tomorrow's growth," Harvard Business Review, no. 62, pp. 153-160, 1984.

[5] T. Luehrman, "Investment opportunities as real options: get started with the numbers," Harvard Business Review, vol. 4, pp. 51-67, 1998.

[6] M. Gallardo and A. Andalaft, "Análisis de la incorporación de flexibilidad en la evaluación de proyectos de inversión utilizando opciones reales y descuento de flujos dinámico," Horizontes Empresariales, vol. 7, no. 1, pp. 41-56, 2008.

[7] P. Lamothe Fernández and M. Pérez Somalo, Opciones Financieras y Productos Estructurados, McGraw-Hill, Madrid, Spain, 2nd edition, 2003.

[8] S. Lee, B. Lee, J. Kim, and J. Kim, "A financing model to solve financial barriers for implementing green building projects," The Scientific World Journal, vol. 2013, Article ID 240394, 10 pages, 2013.

[9] L. Santos, I. Soares, C. Mendes, and P. Ferreira, "Real options versus traditional methods to assess renewable energy projects," Renewable Energy, vol. 68, pp. 588-594, 2014.

[10] C. Bérard and M. Perez, "Alliance dynamics through real options: the case of an alliance between competing pharmaceutical companies," European Management Journal, vol. 32, no. 2, pp. 337-349, 2014.

[11] T. Driouchi and D. J. Bennett, "Real options in management and organizational strategy: a review of decision-making and performance implications," International Journal of Management Reviews, vol. 14, no. 1, pp. 39-62, 2012.

[12] A. Horn, F. Kjærland, P. Molnár, and B. W. Steen, "The use of real option theory in Scandinavia's largest companies," International Review of Financial Analysis, vol. 41, pp. 74-81, 2015.

[13] D. Allenotor and R. K. Thulasiram, "A discrete time financial option pricing model for cloud services," in Proceedings of the IEEE 11th International Conference on Autonomic and Trusted Computing, and IEEE 14th International Conference on Scalable Computing and Communications and Its Associated Workshops, Ubiquitous Intelligence and Computing (UTC-ATC-ScalCom '14), pp. 629-636, Bali, Indonesia, December 2014.

[14] J. Shen and F. Pretorius, "Binomial option pricing models for real estate development," Journal of Property Investment \& Finance, vol. 31, no. 5, pp. 418-440, 2013.

[15] F. Black and M. Scholes, "The pricing of options and corporate liabilities," Journal of Political Economy, vol. 81, no. 3, pp. 637654, 1973.

[16] R. Merton, "The theory of rational options pricing," The Bell Journal of Economics and Management Science, vol. 1, no. 4, pp. 141-183, 1973.

[17] J. C. Cox, S. A. Ross, and M. Rubinstein, "Option pricing: a simplified approach," Journal of Financial Economics, vol. 7, no. 3, pp. 229-263, 1979.

[18] M. Rubinstein, "Implied binomial trees", The Journal of Finance, vol. 49, no. 3, pp. 771-818, 1994.

[19] J. E. Smith and R. F. Nau, "Valuing risky projects: option pricing theory and decision analysis," Management Science, vol. 41, no. 5, pp. 795-816, 1995.

[20] L. E. Brandão, J. S. Dyer, and W. J. Hahn, "Using binomial decision trees to solve real-option valuation problems," Decision Analysis, vol. 2, no. 2, pp. 69-88, 2005.

[21] J. E. Smith, "Alternative approach for solving real options problems," Decision Analysis, vol. 2, no. 2, pp. 89-102, 2005.

[22] Y. G. Xue and M. L. Zhang, "Valuing research investment projects based on discrete time model: a real options approach," Advanced Materials Research, vol. 926-930, pp. 4073-4076, 2014.

[23] H. Xiaoping and J. Cao, "Randomized binomial tree and pricing of American-style options," Mathematical Problems in Engineering, vol. 2014, Article ID 291737, 6 pages, 2014.

[24] A. Damodaran, Investment Valuation: Tools and Techniques for Determining the Value of any Asset, Wiley Finance Publishers, New York, NY, USA, 2nd edition, 2002. 
[25] J. Mascareñas, “Opciones reales: valoración por el método binomial," in Monografías sobre Finanzas Corporativas, Universidad Complutense de Madrid, Madrid, Spain, 2011.

[26] N. L. Damaraju, J. B. Barney, and A. K. Makhija, "Real options in divestment alternatives," Strategic Management Journal, vol. 36, no. 5, pp. 728-744, 2015.

[27] J. Mascareñas, "Opciones reales en la valoración de proyectos de inversión," in Monografías sobre Finanzas Corporativas, Universidad Complutense de Madrid, Madrid, Spain, 2007.

[28] T. Compernolle, S. Van Passel, K. Huisman, and P. Kort, "The option to abandon: stimulating innovative groundwater remediation technologies characterized by technological uncertainty," Science of the Total Environment, vol. 496, pp. 63-74, 2014.

[29] J. Mascareñas and M. Leporati, "Opciones reales y flujo de caja descontado: ¿cuándo utilizarlos?” Nota Técnica 10, Fundació Privada Institut d'Estudis Financers, 2010.

[30] J. Mascareñas, "Opción real de abandonar un proyecto de inversión," in Monografías Sobre Finanzas Corporativas, Universidad Complutense de Madrid, Madrid, Spain, 2014.

[31] H. Smith and L. Trigeorgis, Strategic Investment: Real Options and Games, Princeton University Press, Princeton, NJ, USA, 1st edition, 2004.

[32] M. J. Gordon and E. Shapiro, "Capital equipment analysis: the required rate of profit," Management Science, vol. 3, no. 1, pp. 102-110, 1956.

[33] T. Copeland, T. Koller, and J. Murrin, Valuation: Measuring and Managing the Value of Companies, John Wiley \& Sons, New York, NY, USA, 3rd edition, 2000. 


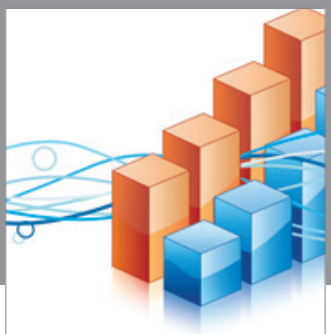

Advances in

Operations Research

vatem alat4

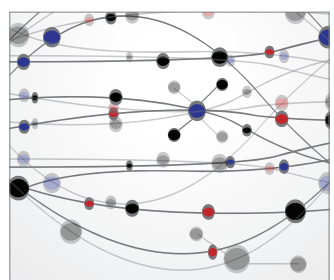

\section{The Scientific} World Journal
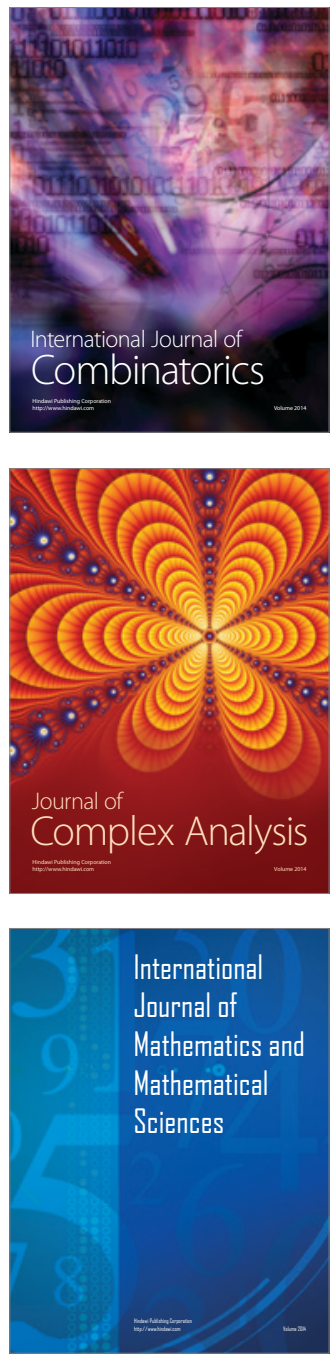
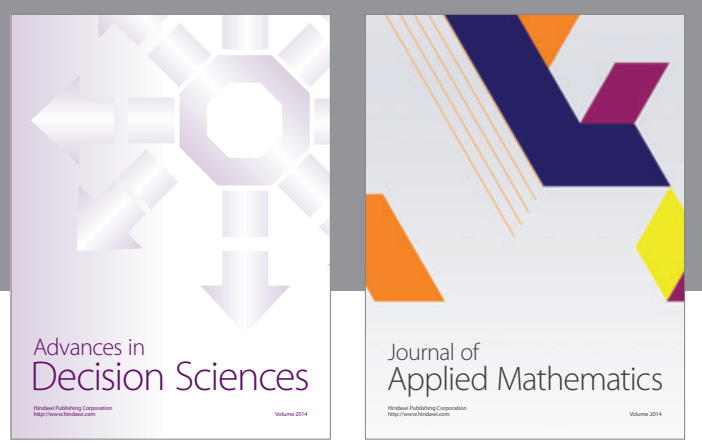

Algebra

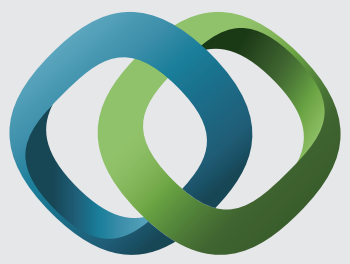

\section{Hindawi}

Submit your manuscripts at

http://www.hindawi.com
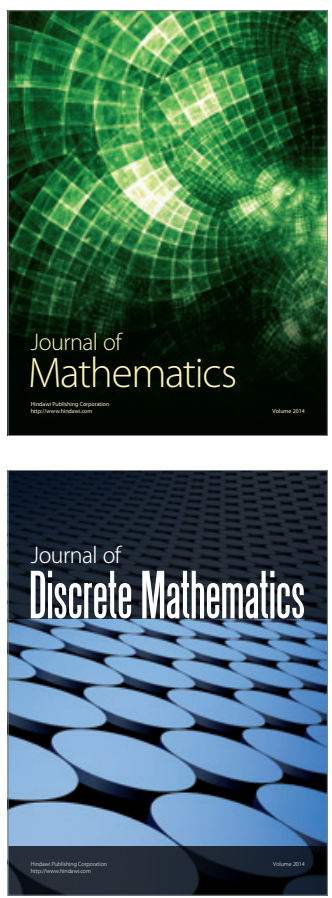

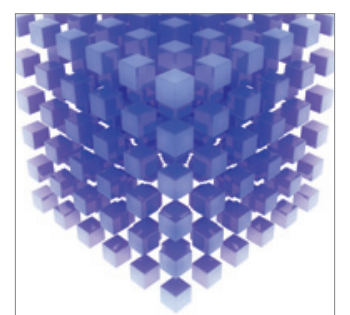

Mathematical Problems in Engineering
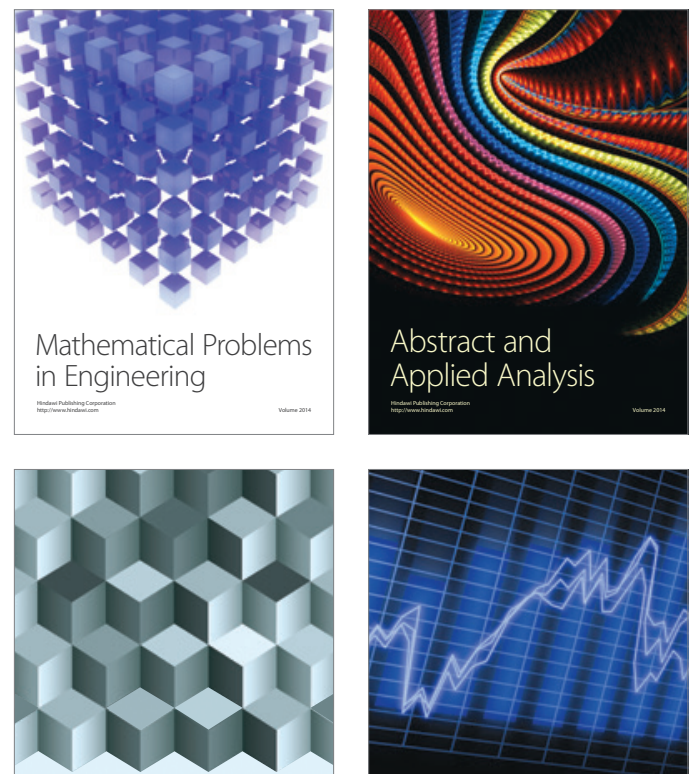

Journal of

Function Spaces

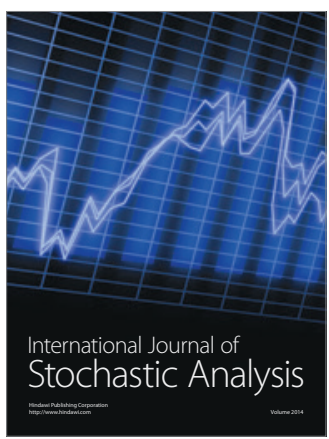

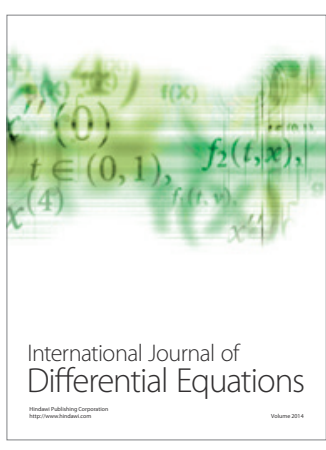
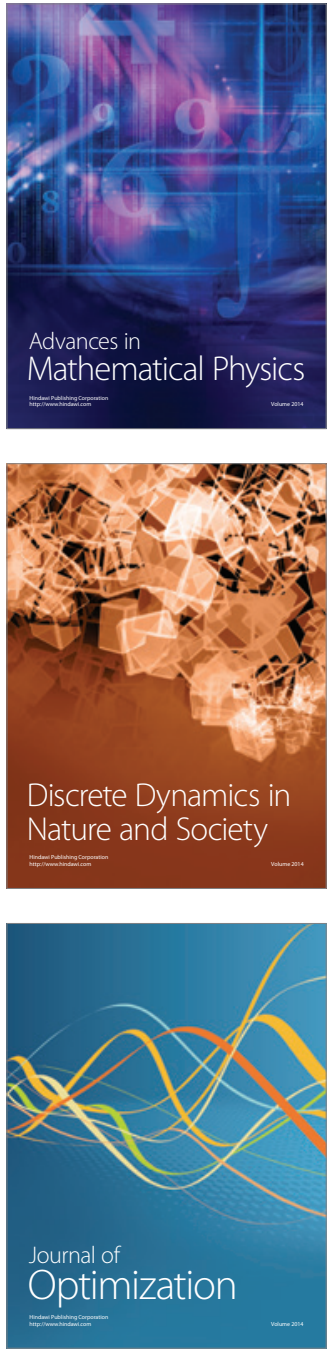